\title{
Pre- and postnatal parental smoking and wheeze in infancy: cross cultural differences
}

\author{
A.J. Henderson*, A. Sherriff*, K. Northstone*, L. Kukla\#, D. Hruba", Avon Study of Parents and \\ Children (ALSPAC) Study Team*, European Longitudinal Study of Pregnancy and Childhood \\ (ELSPAC) Co-ordinating Centre*
}

Pre- and postnatal parental smoking and wheeze in infancy: cross cultural differences. A.J. Henderson, A. Sherriff, K. Northstone, L. Kukla, D. Hruba, Avon Study of Parents and Children (ALSPAC) Study Team, European Longitudinal Study of Pregnancy and Childhood (ELSPAC) Co-ordinating Centre. (C)ERS Journals Ltd 2001.

ABSTRACT: In longitudinal cohort studies, the relationships between prenatal and postnatal tobacco smoke exposure and infant wheezing illnesses were compared in two geographically defined populations in Avon, UK and Brno and Znojmo in the South Moravian Region of the Czech Republic.

Pregnant females living in defined regions and with expected dates of delivery between defined dates were recruited. Females completed self-report questionnaires during pregnancy and when their infant was 6 months old. For this analysis, responses to questions about smoking during pregnancy, environmental tobacco smoke (ETS) exposure and reported wheezing illnesses of infants at 6 months after birth were used. Odds ratios for wheeze in relation to the smoking variables were calculated with adjustment for potential confounding effects.

The prevalence of smoking during pregnancy was higher in Avon (17.5\%) than the Czech Republic (7.1\%). Exposure of infants to ETS during the first 6 months after birth was also reported to be higher in Avon (35.5\%) than the Czech Republic (9.7\%). The prevalence of reported wheezing by 6 months of age was $21.4 \%$ in Avon and $10.3 \%$ in Brno and Znojmo. In Avon, there was a significant relationship between infant wheeze and maternal smoking during pregnancy (odds ratio $(95 \%$ confidence interval) $1.30(1.09-1.56), p=0.004)$ but not with environmental exposure after birth (1.11 (0.98-1.25)). In contrast, in Brno and Znojmo in the Czech Republic, there was a significant relationship between infant wheeze and ETS exposure $(1.66(1.17-2.36)$, $p=0.04)$ but not with maternal smoking during pregnancy $(0.99(0.64-1.55))$.

This study demonstrated an apparent difference in the associations between prenatal and postnatal tobacco smoke exposure and infant wheezing illnesses in two populations with different smoking prevalence. The relationships were independent of a number of potential confounding variables that have been associated with infant wheezing. Possible explanations of these observations include dose-related effects of prenatal and postnatal tobacco smoke exposure of infants.

Eur Respir J 2001; 18: 323-329.
*Institute of Child Health, University of Bristol, UK, ${ }^{\#}$ Research Institute of Child Health, Brno, "Faculty of Medicine, Masaryk University, Brno, Czech Republic.

Correspondence: A.J. Henderson, Institute of Child Health, Royal Hospital for Sick Children, St Michael's Hill, Bristol BS2 8BJ UK.

Fax: 441179292914

Keywords: Infant

pregnancy

respiratory tract diseases

smoking

wheezing

tobacco smoke pollution

Received: February 22000

Accepted after revision February 25 2001

Funding for the Czech Republic study was by Grant Nos. 0208-9 of Internal Grant Agency of the Ministry of Health of the Czech Republic \& NE 6143-2 of Internal Grant Agency of the Ministry of Health of the Czech Republic. The Avon Study of Parents and Children (ALSPAC) has multiple funding sources including the Medical Research Council, National Asthma Campaign, the UK Dept of the Environment, and the Wellcome Trust. Funding for the analyses of smoking effects was provided by the World Health Organization.
Parental smoking has been demonstrated to be associated with adverse respiratory outcomes in children [1]. However, the differential effects of prenatal and postnatal tobacco smoke exposure on the respiratory health of young children have yet to be fully elucidated. Reports of stronger associations between infant respiratory illnesses and maternal smoking than with paternal smoking [2] may represent a congenital effect of tobacco metabolites on intrauterine lung or airway development [3]. Alternatively, increased contact between young children and their mothers could lead to increased exposure to environmental tobacco smoke (ETS) exposure from this source.
Smoking during pregnancy has been associated with diminished lung function [4] and wheeze in infancy $[5,6]$. As the lungs grow, the early propensity to wheezing may diminish, but lung function abnormalities persist [7]. It is likely that intrauterine exposure to tobacco smoke metabolites has a direct effect on lung and airway development. Other effects relevant to wheezing illnesses have also been reported, including up regulation of T-helper cell (Th2) responses [8] and possible increased immunoglobulin-E (IgE) production [9]. However there is currently little direct evidence that in utero exposure to tobacco smoke induces inhalant allergy in children [10]. Passive inhalation of ETS in the postnatal period may 
increase the risk of infant wheezing, either by a direct inflammatory effect on airway mucosa or by increasing susceptibility to respiratory tract infections [11].

Although postnatal exposure is usually considered in statistical models of the effects of prenatal smoke exposure, its independent contribution to the observed outcomes is still unclear. It is difficult to identify populations of infants who are exposed to tobacco smoke during pregnancy and then reared in a smoke free environment, so direct comparisons of infants exposed exclusively to prenatal or postnatal tobacco smoke have not been possible. Comparisons of populations of children who experience different patterns of environmental exposures is one way to examine the differential effects on respiratory outcomes. The prevalence of reported wheezing illnesses was studied in infants from two discrete populations, using similar methodology, to examine the associations with prenatal and postnatal tobacco smoke exposure.

\section{Methods}

The population of infants reported here come from two countries (UK and Czech Republic) that are taking part in the European Longitudinal Study of Pregnancy and Childhood (ELSPAC). This study was designed so that all pregnant females living in a defined geographical region and with expected dates of delivery between defined dates were eligible. Selfreport questionnaires were used to gather information about health, lifestyle and environmental exposures of the mother, her partner and the study child. Identical questions have been asked at repeated intervals over time. Questions about the health of the index child were asked at 6 months of age and have been repeated at 12-monthly intervals. The questionnaire was written in English and translated into Czech. Back translation was used to ensure that the meanings of key words and phrases were retained. The full research protocol for the study has been published previously [12]. Details of all study questionnaires can be viewed on the Avon Study of Parents and Children (ALSPAC) website [13]. Recruitment efficiency was assessed by comparing actual deliveries during the study with actual numbers of females enrolled. As recruitment was based on expected, not actual date of delivery, the proportion of eligible females recruited $(80-85 \%)$ is an approximation but resulted in 14,438 surviving infants in Avon and 5,644 in Brno and Znojmo being enrolled in the longitudinal study. For this study, mother and infant pairs were selected on whom complete data in pregnancy and at 6 months after birth were available (10,683 in Avon and 3,586 in Brno and Znojmo).

\section{Smoking data}

Maternal smoking during the pregnancy was determined from their responses to a questionnaire administered to females at mid-term (18-20 weeks gestation): "How many cigarettes per day did you smoke in the last two weeks?" A range of responses was available: $0 ; 1-4 ; 5-9 ; 10-14 ; 15-19 ; 20-24 ; 25-29$; $\geqslant 30+$. To avoid small numbers of cases in extreme groups, the data were recategorized into none, 1-9 and 10 or more cigarettes per day.

ETS exposure was assessed when the child was 6 months old at the same time as the wheezing data were collected. Responses to the question, "How many hours per day is the baby in a room where there are people smoking?" were used as a marker of total ETS exposure of an individual subject, regardless of who was smoking on weekdays and weekends. It was reasoned that weekend exposure would be the best representation of cumulative individual exposure as this was when infants were exposed to the most diverse groups of smokers. Time of exposure was used to quantify this risk factor to take account of all smoking sources, including outside the family home. The smoking variable was categorized as none, $<1 \mathrm{~h}$, and $\geqslant 1 \mathrm{~h}$ of ETS exposure per day.

\section{Respiratory morbidity}

The presence or absence of wheeze during the first 6 months after birth was based on the mother's response to the question, "Has your child had an episode of wheezing with whistling on the chest?". Supplementary questions were asked about frequency, duration and precipitants of wheezing but, for this analysis, wheeze was considered as a dichotomous variable.

\section{Social and demographic variables (potential confound- ing factors)}

Maternal age was calculated from the mother's date of birth and the infant's date of delivery and maternal parity was defined as the number of previous pregnancies resulting in a live birth or foetal death after 28 completed weeks of gestation. Maternal history of asthma was obtained from a maternal health questionnaire. A "crowding index" was derived for each home by dividing the number of reported occupants during the pregnancy by the number of living rooms and bedrooms available. The sex and gestation of the infant were ascertained at birth, and infant feeding practice was obtained from the maternal questionnaire at 6 months. Season of birth was classified according to the infant's birth date and this was categorized into four quarters (JanuaryMarch; April-June; July-September \& OctoberDecember).

\section{Statistical analysis}

Unadjusted data were compared using Chi-squared or Fisher's exact test with, where appropriate a Chisquared test for trend (Chi-squaredT). Multivariate analyses used logistic regression to determine the associations between the two smoking variables and the dependent dichotomous variable. These were 
Table 1.-Comparisons of maternal smoking rates during pregnancy and reported environmental exposure to tobacco smoke in infants at 6 months of age between the two study centres

\begin{tabular}{|c|c|c|}
\hline & Brno and Znojmo & Avon \\
\hline Subjects $n$ & 3586 & 10683 \\
\hline \multicolumn{3}{|l|}{$\begin{array}{l}\text { Maternal smoking } \\
\text { during pregnancy }\end{array}$} \\
\hline None & $92.9 \%$ & $82.5 \%$ \\
\hline$<10$ cigarettes $\cdot$ day $^{-1}$ & $6.4 \%$ & $8.2 \%$ \\
\hline$\geqslant 10$ cigarettes $\cdot$ day $^{-1}$ & $0.7 \%$ & $9.3 \%$ \\
\hline \multicolumn{3}{|l|}{$\begin{array}{l}\text { Environmental tobacco } \\
\text { smoke exposure }\end{array}$} \\
\hline None & $90.4 \%$ & $64.5 \%$ \\
\hline$<1 \mathrm{~h} \cdot \mathrm{day}^{-1}$ & $6.4 \%$ & $14.3 \%$ \\
\hline$\geqslant 1 \mathrm{~h}$ day $^{-1}$ & $3.3 \%$ & $21.2 \%$ \\
\hline
\end{tabular}

adjusted for the sex of the child, maternal age and parity, gestational age at birth, season of birth, duration of breast feeding and overcrowding ( $>1$ person $\cdot$ room $\left.^{-1}\right)$. Results are presented as an unadjusted and adjusted odds ratio (OR) with $95 \%$ confidence interval (CI). A 5\% significance level was used.

\section{Results}

The proportions of eligible subjects with complete smoking and wheeze data differed between Avon $(10,683 / 14,438 ; 74.0 \%)$ and the Czech Republic (3,586/ 5,$644 ; 63.5 \%$ ) but there was no evidence of selection bias between the two populations. In Avon, $21.5 \%$ of infants wheezed in families where smoking data were available and $22 \%$ for those in whom no smoking data were returned. In the Czech republic, the equivalent proportions were $10.3 \%$ and $10.7 \%$ respectively.

There were differences between Avon, and Brno and Znojmo in both the prevalence of reported maternal smoking during pregnancy and in weekend exposure of infants to ETS (table 1). In Brno and Znojmo, $7.1 \%$ of females reported smoking in pregnancy compared with $17.5 \%$ in Avon. Similar proportions of females in the two regions reported smoking $<10$ cigarettes $\cdot$ day $^{-1}$, but in Avon 9.3\% smoked $\geqslant 10$ cigarettes $\cdot$ day $^{-1}$ compared to only $0.7 \%$ in Brno and Znojmo. For ETS exposure, 35.5\% of infants were reported to be exposed in Avon and 9.7\% in Brno and Znojmo. For the higher of the two exposure categories, the differences were greater with $21.2 \%$ of infants in Avon and 3.3\% of infants in Brno and Znojmo exposed to ETS for $\geqslant 1 \mathrm{~h} \cdot \mathrm{day}^{-1}$.

The prevalence of reported wheeze during the first 6 months after birth was lower in Brno and Znojmo $(10.3 \%)$ than Avon (21.4\%). These data are shown in table 2, which illustrates the relationship between wheezing prevalence, maternal smoking category and ETS exposure in each of the two study regions. In both Avon, and Brno and Znojmo the prevalence of wheezing was higher in infants whose mothers smoked during pregnancy, compared with those whose mothers did not smoke. There appeared to be a stronger association between the number of cigarettes smoked during pregnancy and wheezing prevalence in Avon, compared to the Czech Republic where this association was only apparent in the non-ETS exposed group. For ETS exposure in both regions there was an increased prevalence of wheezing compared to nonexposed infants, but no evidence of a dose-response relationship except for those infants who were not exposed in utero.

The ORs for infant wheeze in relation to each of the environmental and other exposures are shown in table 3. Unadjusted and adjusted ORs are given for each of the two smoking variables. ORs for the other variables are adjusted for the effects of the other risk factors in the logistic regression model. The unadjusted ORs for the smoke exposure variables demonstrate a statistically significant association between infant wheeze and ETS exposure in the Czech data. In the Avon population, the unadjusted ORs support statistically significant associations between wheeze and both prenatal and postnatal ETS exposure. When these were adjusted for each other and the effects of sex, gestation, maternal age and parity, season of birth, maternal history of asthma and overcrowding, the ORs for infant wheeze in the Czech population remained statistically significant for ETS exposure (1.66 (1.17-2.36), $\mathrm{p}<0.05)$. In the Avon population, the adjusted OR for ETS exposure was not statistically

Table 2. - Prevalence of wheezing according to maternal prenatal and environmental postnatal weekend tobacco smoke exposure

\begin{tabular}{|c|c|c|c|c|}
\hline \multirow[b]{2}{*}{ Prenatal smoking } & \multicolumn{4}{|c|}{ Environmental exposure (per weekend day) } \\
\hline & None & $<1$ hour & $\geqslant 1$ hour & All \\
\hline \multicolumn{5}{|l|}{ Brno and Znojmo } \\
\hline None & $9.7(296 / 3065)$ & $14.9(27 / 181)$ & $16.3(14 / 186)$ & $10.1(337 / 3332)$ \\
\hline$<10$ cigarettes $\cdot$ day $^{-1}$ & $9.3(15 / 162)$ & $22.7(10 / 44)$ & $9.1(2 / 22)$ & $11.8(27 / 228)$ \\
\hline$\geqslant 10$ cigarettes $\cdot$ day $^{-1}$ & $30.8(4 / 13)$ & $0(0 / 4)$ & $11.1(1 / 9)$ & $19.2(5 / 26)$ \\
\hline All & $9.7(315 / 3240)$ & $16.2(37 / 229)$ & $14.5(17 / 117)$ & $10.3(369 / 3586)$ \\
\hline \multicolumn{5}{|l|}{ Avon } \\
\hline None & $18.9(1206 / 6367)$ & $19.4(232 / 1195)$ & $24.3(307 / 1263)$ & $19.8(1745 / 8825)$ \\
\hline$<10$ cigarettes $\cdot$ day $^{-1}$ & $24.5(81 / 330)$ & $23.0(47 / 204)$ & $27.7(95 / 343)$ & $25.4(223 / 877)$ \\
\hline$\geqslant 10$ cigarettes $\cdot$ day $^{-1}$ & $29.2(59 / 202)$ & $27.5(38 / 138)$ & $32.8(210 / 641)$ & $31.3(307 / 981)$ \\
\hline All & 19.5 (1346/6899) & $20.6(317 / 1537)$ & $27.5(612 / 2247)$ & $21.4(2275 / 10683)$ \\
\hline
\end{tabular}

Data are presented as \% (proportion of subjects). 
Table 3. - Odds ratios (ORs) and 95\% confidence intervals (Cl) of wheezing episodes during the first 6 months after birth for smoking variables and other environmental variables

\begin{tabular}{|c|c|c|c|c|}
\hline \multirow[t]{3}{*}{ Variable } & \multicolumn{4}{|c|}{ Wheezing episodes } \\
\hline & \multicolumn{2}{|c|}{ Brno \& Znojmo, Czech Republic } & \multicolumn{2}{|c|}{ Avon, UK } \\
\hline & Unadjusted OR $(95 \% \mathrm{CI})$ & Adjusted OR (95\%CI) & Unadjusted OR $(95 \% \mathrm{CI})$ & Adjusted OR $(95 \% \mathrm{CI})$ \\
\hline Subjects n & 3,586 & 3,182 & 10,683 & \\
\hline \multicolumn{5}{|l|}{$\begin{array}{l}\text { Smoking during } \\
\text { pregnancy }\end{array}$} \\
\hline No & 1.00 & 1.00 & 1.00 & 1.00 \\
\hline Yes & $1.12(0.75-1.67)$ & $0.99(0.64-1.55)$ & $1.41(1.20-1.65)$ & $1.30(1.09-1.56)$ \\
\hline p-value & 0.58 & 0.99 & $<0.0001$ & 0.004 \\
\hline \multicolumn{5}{|l|}{$\begin{array}{l}\text { Environmental } \\
\text { tobacco smoke }\end{array}$} \\
\hline No & 1.00 & 1.00 & 1.00 & 1.00 \\
\hline Yes & $1.68(1.22-2.32)$ & $1.66(1.17-2.36)$ & $1.34(1.22-1.47)$ & $1.11(0.98-1.25)$ \\
\hline $\mathrm{p}$-value & 0.001 & 0.04 & 0.001 & 0.09 \\
\hline \multicolumn{5}{|l|}{ Sex } \\
\hline Male & & 1.00 & & 1.00 \\
\hline Female & & $0.83(0.66-1.06)$ & & $0.64(0.58-0.71)$ \\
\hline p-value & & 0.13 & & $<0.0001$ \\
\hline \multicolumn{5}{|l|}{ Season of birth } \\
\hline January-March & & 1.00 & & 1.00 (ref) \\
\hline April-June & & $1.45(1.00-2.11)$ & & $1.54(1.28-1.85)$ \\
\hline July-September & & $1.97(1.34-2.91)$ & & $1.93(1.62-2.30)$ \\
\hline October-December & & $1.75(1.16-2.64)$ & & $1.64(1.37-1.97)$ \\
\hline p-value & & 0.005 & & $<0.0001$ \\
\hline \multicolumn{5}{|l|}{$\begin{array}{l}\text { Maternal age at } \\
\text { delivery }\end{array}$} \\
\hline$>24$ years & & 1.00 & & 1.00 \\
\hline $20-24$ years & & $1.65(1.26-2.17)$ & & $1.14(0.97-1.33)$ \\
\hline$<20$ years & & $1.48(0.89-2.50)$ & & $1.26(0.88-1.80)$ \\
\hline p-value & & 0.001 & & 0.17 \\
\hline \multicolumn{5}{|l|}{ Preterm delivery } \\
\hline$\geqslant 37$ weeks & & 1.00 & & 1.00 \\
\hline$<37$ weeks & & $2.06(0.94-4.51)$ & & $1.49(1.17-1.89)$ \\
\hline p-value & & 0.07 & & 0.001 \\
\hline \multicolumn{5}{|l|}{$\begin{array}{l}\text { Duration of breast } \\
\text { feeding }\end{array}$} \\
\hline None & & 1.00 & & 1.00 \\
\hline$<6$ months & & $0.56(0.32-0.99)$ & & $0.87(0.76-0.99)$ \\
\hline$\geqslant 6$ months & & $0.99(0.61-1.63)$ & & $0.73(0.63-0.84)$ \\
\hline p-value & & 0.003 & & 0.0001 \\
\hline \multicolumn{5}{|l|}{ Maternal parity } \\
\hline 0 & & 1.00 & & 1.00 \\
\hline 1 & & $1.91(1.45-2.51)$ & & $1.79(1.58-2.03)$ \\
\hline$\geqslant 2$ & & $1.95(1.28-2.97)$ & & $2.11(1.81-2.45)$ \\
\hline p-value . & & $<0.0001$ & & $<0.0001$ \\
\hline \multicolumn{5}{|l|}{$\begin{array}{l}\text { Overcrowding in } \\
\text { household }\end{array}$} \\
\hline No & & 1.00 & & 1.00 \\
\hline Yes & & $1.19(0.92-1.53)$ & & $0.98(0.84-1.15)$ \\
\hline p-value & & 0.2 & & 0.823 \\
\hline \multicolumn{5}{|l|}{$\begin{array}{l}\text { Maternal history } \\
\text { of asthma }\end{array}$} \\
\hline No & & 1.00 & & 1.00 \\
\hline Yes & & $1.82(1.10-3.15)$ & & $1.84(1.58-2.14)$ \\
\hline p-value & & 0.03 & & $<0.0001$ \\
\hline
\end{tabular}

ref: reference value.

significant, but there was a highly statistically significant OR for prenatal exposure $(1.30(1.09,1.56)$, $\mathrm{p}=0.0042$ ).

Other factors that were statistically significantly associated with wheezing in the first 6 months after birth showed similar patterns of association in both the Avon and Czech populations. Male sex, preterm birth, and maternal history of asthma were all associated with increased risk of infant wheezing, whereas breast feeding had an apparent protective effect. The season of birth effect also appeared to be similar in Avon, and Brno and Znojmo, with the 
highest OR for wheeze being associated with infants born between July and September.

There was an increased prevalence of wheezing in ETS-exposed infants living in overcrowded conditions $\left(>1\right.$ person $\left.\cdot \mathrm{room}^{-1}\right)$ in the Czech Republic compared to nonexposed infants in similar conditions (18 versus $10.3 \%, \mathrm{p}=0.001)$. This difference was not apparent in Czech infants in nonovercrowded homes nor in Avon children, where the prevalence of overcrowding was low. However, overcrowding was not a statistically significant risk factor in either multivariate model.

\section{Discussion}

This study demonstrated significant wheezing in infants during the first 6 months after birth associated with prenatal and postnatal exposure to tobacco smoke. When these observations were adjusted for each other and for other potential confounding factors, significantly increased ORs were observed for wheeze only, in infants exposed to prenatal maternal smoking independent of postnatal ETS exposure in Avon. In contrast, in the Czech population, only ETS exposure was significantly associated with an increased OR for infant wheeze. Although the Czech population studied was smaller than the Avon population, thus giving less power to detect statistically significant effects, this does not affect the magnitude of the ORs. The observed ORs for other statistically significant risk factors in relation to infant wheeze were remarkably similar between the two populations.

Respiratory illnesses during infancy associated with parental smoking have been demonstrated to be more closely related to maternal than paternal smoking [2]. This may be related to a congenital effect on foetal lung development by intrauterine exposure, or to mothers being the major contributors to infants' ETS exposure in the home [14]. In recent years, there has been increased recognition that infant wheeze is a transient condition in many infants [15]. This may be due to developmental abnormalities of the lung or airways that occur as a result of intrauterine exposure to tobacco smoke metabolites. Several groups have demonstrated abnormalities of lung function in infants shortly after birth, before the effects of environmental exposure become apparent [16-18]. Infants with functional or structural airway abnormalities are more likely to wheeze with respiratory viral infections during infancy. These observations are consistent with the findings in the Avon study, where maternal smoking during pregnancy was associated with infant wheeze. Also, the observations on season of birth in both populations may possibly be explained by infants in the group with the highest risk of wheeze (July-September births) reaching the winter viral season at the nadir of passive maternal immunity and being more prone to respiratory tract infections.

However, the data on smoking obtained from the Czech population are not consistent with this postulated explanation. The present study relied on maternal self-reports of smoking behaviour in both populations and the ELSPAC study design did not allow for measurement of nicotine metabolites such as cotinine in either the mothers or their infants. Therefore, there is no biological validation of these selfreports. Results of a meta-analysis of studies of self-reported smoking have demonstrated that these reports are accurate in most studies, particularly observational and other study designs [19]. Also, the question about smoking was asked before the onset of the health outcomes of interest became apparent. There is no reason to suggest reporting bias in the Czech population, although females under-reporting their own active smoking during pregnancy is one possible explanation for the observations. A study of Czech females in the Brno region has demonstrated urinary cotinine levels in smokers were not significantly different from those in nonsmokers [20]. However, even in females who report smoking during pregnancy, the prevalence of infant wheeze is lower than for Avon smokers in both categories of light and heavy smoking.

It could be speculated that Czech females may smoke in a different way from UK females and inhale a smaller proportion of mainstream smoke. There is little evidence for this. Although cross-cultural studies of smoking behaviour have been done, these have tended to focus on number of cigarettes smoked and have shown differences in the patterns of sociodemographic factors influencing this variable in different populations [21]. A further possible explanation might be the presence of some protective factor for lung injury due to intrauterine tobacco smoke exposure such as vitamin C [22]. Pregnant smokers have been shown to ingest less vitamin $\mathrm{C}$ and other nutrients than pregnant nonsmokers [23]. However, it is unlikely that this explains a difference between the Czech and Avon populations as the intake of vitamin $\mathrm{C}$ in pregnant and nursing mothers in the Czech Republic has been estimated to reach only $65-70 \%$ of recommended daily allowance.

The observed association between wheeze and ETS exposure in the Czech Republic could also have arisen from confounding by unreported maternal smoking during pregnancy. An attempt was made to obtain a proxy measure of total ETS exposure for the index infant, irrespective of its source, but smoking mothers are likely to be major contributors to this total [14]. However, it seems unlikely that mothers would underreport smoking in pregnancy and accurately report postnatal exposure when infants were already symptomatic.

The prevalence and magnitude of ETS exposure was lower in Brno and Znojmo than in Avon, but was significantly associated with an increased prevalence of infant wheezing. It may be that the duration of exposure was short, but the intensity of exposure was very high in this population. Overcrowding was examined as a possible proxy for intensity of exposure, reasoning that infants exposed to ETS in overcrowded conditions were likely to be exposed to higher levels of passive smoke. There was some evidence of this in the univariate analysis, but the effect was not statistically significant when adjusted for other variables in a multivariate model.

Wheezing was studied only up until the age of 
6 months in these populations. Wheezing that results from abnormal intrauterine lung development is likely to be manifest during this period [6] and may persist up to the age of 3 yrs [7]. It might be argued that the follow-up was not continued for long enough to recognize postnatal effects, but significant associations were observed with other factors that have been associated with increased risk of wheezing and an independent effect of postnatal ETS exposure was found in the Czech population. The follow-up of the Avon population has been continued, and recent studies have demonstrated independent effects of prenatal and postnatal smoking on wheeze during later childhood [24]. The observation of a postnatal but not a prenatal effect of smoking on infant wheeze in the Czech population is largely unexplained and further studies using objective measurements of nicotine metabolites may help to elucidate the mechanisms for this finding.

International collaborative studies have recently highlighted important differences in the prevalence of common childhood respiratory disorders in different countries [25]. Detailed analyses of environmental factors for which there is reasonable prior evidence for a role in such disorders in cross-cultural, epidemiological studies may yield important differential associations. These in turn may help to guide further studies of causal factors in common childhood disorders such as asthma and wheezing.

\footnotetext{
Acknowledgements. European Longitudinal Study of Pregnancy and Childhood (ELSPAC) is an initiative of the World Health Organisation (WHO). This study is the result of a massive effort by ELSPAC parents and children and the survey teams in the respective countries.

The ELSPAC Co-ordinating Centre: J. Golding, Head of Centre; H. Simmons, Programme Manager; S. Preece, Translations and backtranslations, editing and documenting, A. Boyd, Collating and editing data.

Czech Republic: L. Kukla, Dept of Social and Preventive Pediatry, Research Institute of Child Health; M. Bouchalova, Epidemiologist; D. Hruba, Masaryk University Medical Faculty; M. Tyrlik, Masaryk University Philosophical Faculty; J. Hrdinova, Paediatrician; J. Balharova, Paediatrician; I. Samsula, Computer Technician; J. Vaclavkova, Social Worker; V. Krejci, Secretary; V. Vacova, Field Worker/ Family Visitor; J. Klimesova, Field Worker/ Family Visitor; S. Bizikova, Field Worker/ Family Visitor; Z. Hudcova, Coder; J. Stastna, Keyboard Operator; I. Rojkova, Keyboard Operator; J. Winkler, Sociologist; P. Mikyska, Paediatrician, Znojmo; M. Novakova, Children's Nurse, Znojmox.

Avon: Members of the ALSPAC Study Team are listed on the ALSPAC web site [13].
}

\section{References}

1. Strachan DP, Cook DG . Health effects of passive smoking. I. Parental smoking and lower respiratory tract illnesses in infancy and childhood. Thorax 1997; 52: $905-914$.
2. Taylor B, Wadsworth J. Maternal smoking during pregnancy and lower respiratory tract illness in early life. Arch Dis Child 1987; 62: 786-791.

3. Chen MF, Kimizuka G, Wang NS. Human foetal lung changes associated with maternal smoking during pregnancy. Pediatr Pulmonol 1987; 3: 51-58.

4. Stick SM, Burton PR, Gurrin L, Sly PD, LeSouëf PN. Effect of maternal smoking during pregnancy and a family history of asthma on respiratory function in newborn infants. Lancet 1996; 348: 1060-1064.

5. Martinez FD, Morgan WJ, Wright Al, Holberg CJ, Taussig LM. Diminished lung function as a predisposing factor for wheezing respiratory illness in infants. N Engl J Med 1988; 319: 1112-1117.

6. Dezateux C, Stocks J, Dundas I, Fletcher ME. Impaired airway function and wheezing in infancy: the influence of maternal smoking and a genetic predisposition to asthma. Am J Respir Crit Care Med 1999; 159: 403-410.

7. Martinez FD, Wright AL, Taussig LM, Holberg CJ, Halonen M, Morgan WJ. Asthma and wheezing in the first six years of life. N Engl J Med 1995; 332: 133-138.

8. Seymour BW, Pinkerton KE, Friebertshauser KE, Coffman RL, Gershwin LJ. Second-hand smoke is an adjuvant for $\mathrm{T}$ helper-2 responses in a murine model of allergy. J Immunol 1997; 159: 169-175.

9. Kjellman NI. Effect of parental smoking on IgE levels in children (letter). Lancet 1981; 1: 993-994.

10. Strachan DP, Cook DG. Health effects of passive smoking. 5. Parental smoking and allergic sensitization in children. Thorax 1999; 53: 117-123.

11. Li JS, Peat JK, Xuan W, Berry G. Meta-analysis on the association between environmental tobacco smoke (ETS) exposure and the prevalence of lower respiratory tract infection in early childhood. Pediatr Pulmonol 1999; 27: 5-13.

12. Golding J, Pembrey M, Jones R and ALSPAC Study Team. ALSPAC - The Avon Longitudinal Study of Parents and Children. I. Study methodology. Paediatr Perinatal Epidemiol 2001; 15: 74-87.

13. http://www.ich.bristol.ac.uk/alspac.html

14. Jordaan ER, Ehrlich RI, Potter P. Environmental tobacco smoke exposure in children: household and community determinants. Arch Environ Health 1999; 54: 319-327.

15. Martinez FD, Morgan WJ, Wright AL, Holberg C, Taussig LM. Initial airway function is a risk factor for recurrent wheezing respiratory illnesses during the first three years of life. Am Rev Respir Dis 1993; 143: 312 316.

16. Milner AD, Marsh MJ, Ingram DM, Fox GF, Susiva G. Effects of smoking in pregnancy on neonatal lung function. Arch Dis Child 1999; 80: F8-14.

17. Brown RW, Hanrahan JP, Castile RG, Tager IB. Effect of maternal smoking during pregnancy on passive respiratory mechanics in early infancy. Pediatr Pulmonol 1995; 19: 23-28.

18. Hanrahan JP, Brown RW, Carey VJ, Castile RG, Speizer FE, Tager IB. Passive respiratory mechanics in healthy infants. Effects of growth, gender and smoking. Am J Respir Crit Care Med 1997; 155: 18151816.

19. Patrick DL, Cheadle A, Thompson DC, Diehr P, Koepsell T, Kinne S. The validity of self-reported smoking: a review and meta-analysis. Am $J P u b$ Health 1994; 84: 1086-1093.

20. Goldber H, Velebil P, Stembera Z, et al. Czech 
Republic Reproductive Health Survey. Center for Disease Control and Prevention, USA, 1995

21. King G, Grizeau D, Bendel R, Dressen C, Delaronde SR. Smoking behaviour among French and American women. Prev Med 1998; 27: 520-529.

22. Maritz GS, van Wyk G. Influence of maternal nicotine exposure on neonatal lung structure: protective effect of ascorbic acid. Endocrinology 1997; 117: 159-165.

23. Trygg K, Lud-Larsen K, Sandstad B, Hoffman HJ, Jacobsen G, Bakketeig LS. Do pregnant smokers eat differently from pregnant non-smokers? Pediatr Perinatal Epidemiol 1995; 9: 307-319.

24. Lux AL, Henderson AJ, Pocock SJ. Wheeze associated with prenatal tobacco smoke exposure: a prospective, longitudinal study. Arch Dis Child 2000; 83: 307-312.

25. Anonymous. Worldwide variations in the prevalence of asthma symptoms: The International Study of Asthma and Allergies in Childhood (ISAAC). Eur Respir J 1998; 12: 315-335. 